\title{
Seroprevalencia y factores de riesgo del virus de parainfluenza 3 (VPI-3) en bovinos de Colombia
}

\author{
Fernández, M.A.; Bulla, D.M; Díaz, A.M.; Pulido, M.O. \\ Universidad Pedagógica y Tecnológica de Colombia, Grupo de \\ Investigación en Medicina Veterinaria y Zootecnia, Boyacá, Colombia. \\ E-mail: dianabullamvz17@gmail.com
}

\begin{abstract}
Resumen
Fernández, M.A.; Bulla, D.M.; Díaz, A.M.; Pulido, M.O.: Seroprevalencia y factores de riesgo del virus de parainfluenza 3 (VPI-3) en bovinos de Colombia. Rev. Vet. 31: 2, 155-159, 2020. El virus de la parainfluenza bovina tipo 3 (VPI-3) es considerado como uno de los patógenos más importantes asociados con las enfermedades respiratorias bovinas. Está calificado como parte del complejo respiratorio bovino, porque es una enfermedad multifactorial asociada a la manifestación de diferentes agentes etiológicos que causan neumonía o infección de las vías respiratorias superiores, en todas las edades del ganado. Está ampliamente distribuido a nivel mundial y se caracteriza por causar síntomas como bronconeumonía grave, tos, anorexia, pirexia, secreciones nasales y oculares, disnea y -a veces- diarrea. El objetivo de esta investigación fue determinar la seroprevalencia y los factores de riesgo del virus de parainfluenza en bovinos del municipio de Oicatá (Boyacá, Colombia). Se recolectaron 360 muestras de sangre de hembras bovinas, las cuales se procesaron mediante la implementación del kit comercial ELISA PrimacheckVPI-3®, Agrolabo (España). La seroprevalencia de VPI-3 fue del 31\%, sin embargo no se encontró asociación estadística con la raza y edad de los individuos evaluados. La seroprevalencia de la enfermedad es elevada en Oicatá, afectando directamente a la productividad y rentabilidad de la producción animal, razón por la cual se hace necesaria la implementación de planes de control y prevención de dicha patología.
\end{abstract}

Palabras clave: bovino, virus de parainfluenza VPI-3, ELISA, prevalencia, Colombia.

\begin{abstract}
Fernández, M.A.; Bulla, D.M.; Díaz, A.M.; Pulido, M.O.: Seroprevalence and risk factors of the parainfluenza virus (VPI-3) in cattle from Colombia. Rev. Vet. 31: 2, 155-159, 2020. Bovine parainfluenza virus ty pe 3 (IPV-3) is considered one of the most important pathogens associated with bovine respiratory diseases. It is considered as a part of the bovine respiratory complex, since it is a multifactorial disease associated with the manifestation of different etiological agents that cause pneumonia or upper respiratory tract infections in all cattle ages. It is widely distributed worldwide and is characterized by causing symptoms such as severe bronchopneumonia, cough, anorexia, pyrexia, nasal and eye secretions, dyspnea and sometimes diarrhea. The objective was to determine the seroprevalence and risk factors of parainfluenzavirus (IPV-3) in cattle from the Oicatá (Boyacá, Colombia). Blood samples were collected from 360 bovine females, which were processed in the Veterinary Parasitology Laboratory of the Colombia University through the implementation of the ELISA Primacheck (Agrolabo, Spain). The seroprevalence of IPV-3 in the municipality of Oicatá was $31 \%$, however, no statistical association was found with the breed and age of the individuals evaluated. The seroprevalence of the disease is high in this municipality, which directly affects the productivity and profitability of productions, for this reason it is necessary to implement control and prevention plans for this pathology.
\end{abstract}

Key words: bovine, parainfluenza virus type, enzyme-linked immune-sorbent assay, prevalence, Colombia.

\section{INTRODUCCIÓN}

El complejo respiratorio bovino es una enfermedad importante que afecta a la industria ganadera mundial,

Recibido: febrero 2020 / Aceptado: julio 2020 siendo considerada como la causa de alta morbilidad y mortalidad, de diagnóstico común en el ganado ${ }^{17,25}$. Es una patología multifactorial asociada con la susceptibilidad del huésped, las condiciones ambientales, el manejo de los animales, la presencia y la carga de patógenos ${ }^{4,17,18}$. 
Generalmente se presenta como neumonía o infecciones de las vías respiratorias superiores en todas las edades del ganado, particularmente en los bovinos jóvenes ${ }^{5,12}$.

Bacterias patógenas como Mannheimia haemolytica, Pasteurella multocida, Histophilus somni y Mycoplasma bovis junto al virus sincitial respiratorio bovino, coronavirus bovino, virus de parainfluenza bovina tipo 3 , virus de diarrea viral bovina y herpesvirus bovino tipo 1 están asociados con este complejo ${ }^{20}$.

La infección provoca inflamación y daños en el tracto respiratorio, con casos graves que resultan en la muerte. La patogénesis se ha atribuido a una infección viral primaria y a la posterior colonización bacteriana del epitelio comprometido que causa una infección secundaria $^{4,24}$. La interacción viral con el sistema inmune puede conducir a la supresión de la inmunidad, lo cual perjudica las respuestas del huésped a las infecciones bacterianas secundarias?

A pesar de su etiología multifactorial, las pruebas de diagnóstico actualmente disponibles para el complejo de enfermedades respiratorias bovinas son ensayos de un solo patógeno ${ }^{26}$. Dentro de ellos, el virus de la parainfluenza bovina tipo 3 (VPI-3) es considerado como uno de los patógenos más importantes asociados con las enfermedades respiratorias bovinas en ganado joven y adulto en todo el mundo ${ }^{15}$. Este germen es miembro del género Respirovirus de la familia Paramy xoviridae y del orden Mononegavirales, siendo un virus envuelto con un genoma de ARN de sentido negativo monocatenario no segmentado ${ }^{13,16}$.

VPI-3 puede causar enfermedades respiratorias bovinas como neumonía y bronconeumonía tanto en animales jóvenes como en adultos ${ }^{17,28,30}$, infectando a una amplia variedad de mamíferos, incluidos humanos, animales domésticos y animales salvajes ${ }^{22}$. Si bien la mayoría de las infecciones agudas son subclínicas, pueden causar enfermedades respiratorias caracterizadas por tos, fiebre y secreción nasal ${ }^{19}$.

Las pérdidas causadas como consecuencia de la prevalencia del VPI-3 en asociación con otros tipos de virus en bovinos ascienden al 15\%. Sumado a esto, el desconocimiento de la incidencia de este virus sobre factores reproductivos conlleva a la necesidad de realizar investigaciones que aporten nueva información ${ }^{5}$; además el diagnóstico rápido de la enfermedad podría contribuir en gran medida a contener las epidemias y así evitar pérdidas económicas ${ }^{29}$

El objetivo de la presente investigación fue determinar la seroprevalencia y factores de riesgo asociados a la presentación del virus de parainfluenza bovina tipo 3 en el municipio de Oicatá, Boyacá.

\section{MATERIAL Y MÉTODOS}

Área de estudio. Las muestras fueron recolectadas en el Municipio de Oicatá, departamento de Boyacá, Colombia. El predio posee una extensión total de 59
$\mathrm{Km}^{2}$, se encuentra en una altitud de $2.815 \mathrm{msnm}$ y posee una temperatura promedio de $14^{\circ} \mathrm{C}$.

Animales y tamaño de muestra. La investigación corresponde a un análisis estadístico, de corte transversal, con muestreo aleatorio simple. A partir de la población registrada para el municipio de 6.324 animales ${ }^{11}$, se calculó el tamaño de la muestra mediante la ecuación descrita por Pourhoseingholi et al. en el $2013^{21}$, donde $\mathrm{N}=6.324 \mathrm{Za}=1,96$ a un nivel de confianza del $95 \%$, $\mathrm{e}=$ $5 \%$, margen de error admitido, $\mathrm{P}=50 \%$, prevalencia esperada debido a que en Oicatá no se conocen estudios relacionados de seroprevalencia de parainfluenza tipo 3 en bovinos. El tamaño de muestra calculado para este estudio fue de 360 animales. Se tuvieron en cuenta las variables edad y raza de los bovinos. Los animales seleccionados fueron hembras lecheras entre 2 y 4 años, correspondientes a las razas: Holstein, Jersey, Ayrshire y Normando. Además, se determinaron variables de tipo reproductivo como aborto, repetición de celos, muerte embrionaria, nacimiento de terneros débiles y distocias en las hembras bovinas que pudieran tener relación con la presencia de la enfermedad.

Recolección y procesamiento de muestras. La punción se realizó en la vena coccígea. La higienización de la zona se efectuó utilizando jabón quirúrgico, yodo y alcohol. La sangre se almacenó en tubos tapa roja. Se recolectaron $5 \mathrm{~cm}^{3}$ de sangre, se rotularon y se almacenaron en un cava de refrigeración para luego ser transportados al laboratorio de Parasitología Veterinaria de la Universidad Pedagógica y Tecnológica de Colombia (Uptc) Tunja, Boyacá, Colombia. Una vez en el laboratorio se centrifugaron a $3500 \mathrm{rpm}$ durante 10 minutos. Posteriormente el suero fue recolectado y transferido a un tubo Eppendorf de $2 \mathrm{ml}$ para su almacenamiento a $-20^{\circ} \mathrm{C}$. Las muestras se procesaron bajo la técnica de ELISA indirecta para la detección de anticuerpos anti-PI-3 (Parainfluenza 3 bovina) (ELISA Primacheck PI-3®, Agrolabo S.p.A, España). Para la determinación de muestras positivas y negativas se siguió el instructivo del kit

Análisis de datos. Se utilizó la prueba de independencia de chi-cuadrado. Junto a ésta se utilizó el coeficiente de contingencia de Pearson, para determinar la relación entre las variables edad y reactividad serológica al VPI-3. Para establecer la relación entre el factor de riesgo y la enfermedad se utilizó la medida de asociación o de efecto OR (Odds Ratio), medida epidemiológica para determinar los grados de asociación.

Consideraciones éticas. El estudio se realizó de acuerdo con la Resolución 8430 de 1993 del Ministerio de Salud y de Protección Social de Colombia y la ley 84 de 1989, que establecen las normas de bienestar de los animales durante la investigación. Se obtuvo consentimiento informado por parte de los propietarios de los bovinos antes de tomar las muestras de sangre. 


\section{RESULTADOS}

De las 360 hembras bovinas analizadas, 113 presentaron reactividad al VPI-3 lo cual equivale a una prevalencia de $31 \%$ en el municipio de Oicatá- Boyacá. Las seroprevalencias para los grupos etarios fueron de $15 \%$ para el grupo de bovinos mayor de 2 años, seguida de $16 \%$ para bovinos $>4$ años y la más alta fue para el grupo de más de 3 años (69\%). No se encontraron asociaciones estadísticas significativas $(p \geq 0,05)$.

$\mathrm{Al}$ analizar la variable raza se encontró que el ganado Jersey presentó mayor seroprevalencia con $47 \%$, seguida de la raza Holstein con $26 \%$, Ay rshire con $16 \%$ y para la raza Normando se obtuvo un $12 \%$ de seropositividad. Por su parte, el análisis de asociación reveló que no hubo relación entre la variable raza (Jersey, Holstein, Normando y Ayrshire) con la seropositividad al VPI-3.

En la Tabla 1 se presentan los resultados hallados para la relación entre la seropositividad a la enfermedad y la presentación de eventos reproductivos. La repetición de calores $(15,5 \%)$, fue el evento que ocurrió con mayor frecuencia, seguida por los abortos $(12,7 \%)$, las distocias $(9,7 \%)$, muerte embrionaria $(6,6 \%)$ y terneros débiles al nacer $(3,6 \%)$.

Tabla 1. Seroprevalencia del virus de parainfluenza bovina 3 (VPI-3) para variables reproductivas en el municipio de Oicatá-Boyacá.

\begin{tabular}{lccc}
\hline evento reproductivo & parámetro & positivo & prevalencia (\%) \\
\hline \multirow{2}{*}{ aborto } & sí & 67 & 12,7 \\
& no & 46 & 18,6 \\
repetición de calores & sí & 56 & 15,5 \\
\multirow{2}{*}{ distocias } & no & 57 & 15,8 \\
& sí & 35 & 9,7 \\
terneros débiles al nacer & no & 78 & 21,6 \\
& sí & 13 & 3,6 \\
muerte embrionaria & sí & 100 & 27,7 \\
& no & 84 & 6,6 \\
\hline
\end{tabular}

Al evaluar la relación de la variable aborto con la seropositividad a la enfermedad, se obtuvo un valor de Odds Ratio de 1,026 ( $\mathrm{IC}=1,03-0,97)$ lo que podría significar una relación positiva de la enfermedad con este evento, convirtiendo al VPI-3 en un posible factor de riesgo para la ocurrencia del aborto. Frente al factor repetición de celo, se tuvo un OR de 0,94 (IC $=0,94$ $-1,06)$, es decir, no representó factor de riesgo.

Además, al evaluar las hembras que tuvieron partos distócicos se obtuvo un OR de 0,91 (IC= 0,92-1,09), demostrando que no hay asociación estadísticamente relevante. Para la variable terneros débiles al nacer, se obtuvo un valor para $\mathrm{OR}=0,73$, IC $(0,74-1,36)$, el cual indica que no hay relación entre este evento y la presentación de la enfermedad. De igual forma, para las hembras con muerte embrionaria, se determinó un $\mathrm{OR}=2,2$, IC $(0,74-1,36)$, lo que indica que la enfermedad es posible factor de riesgo para la presentación de este evento.

\section{DISCUSIÓN}

VPI-3 es una infección endémica reconocida desde hace mucho tiempo, actualmente poco encontrada en poblaciones de ganado lechero y de carne alrededor del mundo ${ }^{8}$; sin embargo, los resultados obtenidos en el municipio de Oicatá-Boyacá mediante detección serológica del virus, permitieron establecer que la seroprevalencia reportada en el país, es mayor a la obtenida en el municipio de Montería en donde se encontró un valor de $13,5 \%{ }^{5}$, significativamente menor a la determinada en Aguachica y Rio de Oro (César) con una prevalencia de $88 \%{ }^{9}$.

Estas variaciones se pueden deber a la cantidad de individuos muestreados, a la técnica diagnóstica implementada y a las condiciones sanitarias y de manejo de las producciones que participaron en el estudio, pues en las enfermedades asociadas con el complejo respiratorio como VPI-3 se deben tener en cuenta variables como la susceptibilidad del huésped, las condiciones ambientales y el manejo de los animales ${ }^{4,17}, 18$.

A nivel internacional se han reportado seroprevalencias variables de VPI-3, en Perú se determinó un valor del $81,8 \% \%^{6}, 85,6 \%$ en México ${ }^{23}, 93,3 \%$ en Ecuador ${ }^{3}$ y $34 \%$ en bisontes europeos de Polonia ${ }^{14,27}$, valores superiores al reportado en el municipio de Oicatá (Boyacá).

En cuanto a los grupos etarios, los ejemplares mayores a tres años pero menores de cuatro, presentaron la seroprevalencia más alta (69\%). Sin embargo, estos resultados no concuerdan con lo reportado por otros investigadores ${ }^{5,14,23}$, quienes encontraron las mayores prevalencias en los individuos $\geq 7$ años (20\%), de 9 a 12 años $(95 \%)$ y mayores de 4 años $(48,8 \%)$. Asimismo, estos autores reportaron la menor seroprevalencia en individuos de 3-4 años, con valores de $69 \%{ }^{23}$ y $5,7 \%{ }^{5}$; así como en animales menores a un año $(9,4 \%)^{14}$.

Aunque los valores y los grupos evaluados en cada investigación no son iguales, concuerdan en que las prevalencias más bajas se presentaron en el grupo etario de menor edad de cada trabajo, sin embargo, es importante resaltar que la presentación de la enfermedad clínica es más común en terneros con transferencia pasiva deficiente o anticuerpos maternos en descomposición ${ }^{8,12}$.

Asímismo, no se encontró asociación estadística significativa $(p \geq 0,05)$ entre la presentación de VPI-3 y la edad de los bovinos evaluados en el municipio de Oicatá (Boyacá), resultados que no concuerdan con lo reportado por Solís en $2007^{23}$, Betancur y colaboradores en $2010{ }^{5}$ y Krzysiak et al en $2018{ }^{14}$, quienes sí encontraron relación estadística significativa entre la variable y la presentación de la enfermedad, lo que indica que la presentación del virus está relacionada con la edad de los bovinos evaluados.

En relación a las razas evaluadas, los bovinos Jersey presentaron mayor seroprevalencia con $47 \%$, seguida de la raza Holstein con $26 \%$, sin embargo, estos resultados no concuerdan con lo reportado por Andrade 
y Chicaiza ${ }^{3}$, quienes encontraron una seroprevalencia del $100 \%$ y $88,7 \%$ en ganado Holstein puro y Holstein puro registrado respectivamente, y lo atribuyeron a la mayor rusticidad en el ganado Holstein puro registrado, la cual ocurriría por la alta heterosis en los animales con menor pureza, condición que podría explicar el porqué de la baja seroprevalencia en los bovinos de la raza Normando.

En términos de fertilidad, la capacidad de los virus para causar abortos y malformaciones fetales han recibido gran atención ${ }^{2}$. La prevalencia de VPI-3 fue más alta en aquellos animales que tuvieron repetición de celos y la presentación de abortos como eventos reproductivos, resultados que concuerdan con lo reportado por Betancur ${ }^{5}$, quien determinó que en relación a las tasas de prevalencia de VPI-3 positivas, las repeticiones de servicios fueron las más altas, seguidas de los abortos. Las causas de presentación de abortos en bovinos son diversas y tienen muchas etiologías potenciales que a menudo son difíciles de diagnosticar de manera confiable ${ }^{10}$.

Sin embargo, existe evidencia significativa de que las infecciones virales tienen acciones adicionales en las vacas lecheras, que se reflejan en tasas reducidas de concepción. No obstante, estos efectos dependen mucho del momento en que el animal contrae la enfermedad por primera vez, o de la etapa de preñez durante la cual ocurre la infección viral inicial ${ }^{27}$.

Asimismo, los efectos de las enfermedades virales en el rendimiento reproductivo son mucho más generalizados y pueden tener muchos efectos sutiles a través de la reducción de las tasas de concepción y un mayor riesgo de sacrificio por no concebir de manera oportuna ${ }^{27}$.

Teniendo en cuenta los datos reportados en otras regiones del país, se puede determinar que la frecuencia serológica del VIP-3 es elevada en el municipio de Oicatá- Boyacá debido a que se encontró una seroprevalencia del $31 \%$, en donde los bovinos de la raza Jersey $\mathrm{y}$ los individuos $>3$ años presentaron los porcentajes de infección más elevados.

Por esta razón se hace necesaria la implementación de un programa de medicina preventiva que permita el control de diseminación de la enfermedad dentro y fuera del municipio. Asímismo, se deben realizar investigaciones que permitan establecer la asociación de este virus con las manifestaciones clínicas respiratorias y con los demás agentes causales del complejo respiratorio bovino.

\section{REFERENCIAS}

1. Alcaldía Municipal de Oicatá. 2019. Nuestro municipio [Internet], disponible en http://www.oicata-boyaca.gov.co.

2. Ali H, Ali AA, Atta MS, Cepica A. 2012. Common, emerging, vector-borne and infrequent abortogenic virus infections of cattle. Transbound Emerg Dis 59: 11-25.

3. Andrade OS, Chicaiza G. 2015. Prevalencia de anticuerpos a parainfluenza bovina (PI-3) en ganaderías lecheras de Cuenca, Ecuador. Maskana 8: 209-210.
4. Angen $\mathrm{O}$ et al. 2009. Respiratory disease in calves: microbiological investigations on trans-tracheally aspirated bronchoalveolar fluid and acute phase protein response. Vet Microbiol 137: 165-171.

5. Betancur HC, Orrego UA, González TM. 2010. Estudio seroepidemiológico del virus de parainfluenza-3 en bovinos de Montería (Colombia) con trastornos reproductivos. Rev MedVet 20: 63-70.

6. Cabello RK, Quispe CR, Rivera GH. 2006. Frecuencia de los virus parainfluenza-3, respiratorio sincitial y diarrea viral bovina en un rebaño mixto de una comunidad campesina de Cusco. Rev Investig Vet Peru 17: 167-172.

7. Czuprynski CJ et al. 2004. Complexities of the pathogenesis of Mannheimia haemolytica and Haemophilus som$n u s$ infections: challenges and potential opportunities for prevention? Anim Heal Res Rev 5: 277-282.

8. Ellis JA. 2010. Bovine parainfluenza-3 virus. In: Veterinary Clinics of North America - Food Animal Practice, Elsevier Ltd, p. 575-593.

9. Gálvis GT, Bautista AH, Vásquez MC. 2016. Prevalencia de anticuerpos contra diarrea viral bovina, virus sincitial bovino, rinotraqueitis infecciosa bovina, leucosis bovina, neospora caninum, parainfluenza bovina (PI3) y paratuberculosis, en ganadería bovina de fincas ubicadas en Aguachica. Rev Fac Ciencias Salud 3: 36

10. Givens DM, Marley MS. 2008. Infectious causes of embryonic and fetal mortality. Theriogenology 70: 270-285.

11. ICA: Censo Pecuario Nacional. 2019. Disponible en: https:/www.ica.gov.co/areas/ pecuaria/servicios/epidemiologia-veterinaria/censos-2016/censo-2018.

12. Karle BM et al. 2019. Regional management practices and prevalence of bovine respiratory disease in California's preweaned dairy calves. J Dairy Sci 102: 7583-7596.

13. Karron RA, Collins PL. 2013. Parainfluenza viruses. In: Fields Virology, Knipe DM \& Howley PM editors, 6th ed., Philadelphia, p. 996-1023.

14. Krzysiak MK et al. 2018. Seroprevalence and risk factors for selected respiratory and reproductive tract pathogen exposure in eu ropean bison (Bison bonasus) in Poland. Vet Microbiol 215: 57-65.

15. Lv L, Zhao G, Wang H, He H. 2019. Cholesterol 25-hydroxylase inhibits bovine parainfluenza virus type 3 replication through enzyme activity-dependent and independent ways. Vet Microbiol 239: 108456.

16. Maidana SS et al. 2012. Isolation and characterization of bovine parainfluenza virus type 3 from water buffaloes (Bubalus bubalis) in Argentina. Vet Res 8: 83-91.

17. Murray GM et al. 2017. Evolving views on bovine respiratory disease: An appraisal of selected key pathogens. Vet J 217: 95-102.

18. Murray GM et al. 2016. Pathogens, patterns of pneumonia, and epidemiologic risk factors associated with respiratory disease in recently weaned cattle in Ireland. $J$ Vet Diagn Investig 29: 20-34

19. Neill JD, Ridpath JF, Valayudhan BT. 2015. Identification and genome characterization of genotype $\mathrm{B}$ and genotype $\mathrm{C}$ bovine parainfluenza type 3 viruses isolated in the United States. BMC Vet Res 11: 1-6. 
20. Pansri P et al. 2020. Evaluation of novel multiplex qPCR assays for diagnosis of pathogens associated with the bovine respiratory disease. Vet $J$ 256: 105425.

21. Pourhoseingholi MA, Vahedi M, Rahimzadeh M. 2013. Sample size calculation in medical studies. Gastroenterol Hepatol from Bed to Bench 6: 14-17.

22. Sobhy NM et al. 2017. Surveillance, isolation and complete genome sequence of bovine parainfluenza virus type 3 in Egyptian cattle. Int J Vet Sci Med 5:8-13.

23. Solís JJ, Segura JC, Aguilar F, Segura VM. 2007. Detection of antibodies and risk factors for infection with bovine respiratory syncytial virus and parainfluenza virus-3 in beef cattle of Yucatan, Mexico. Prev Vet Med 82: 102110.

24. Sudaryatma PE et al. 2018. Bovine respiratory syncytial virus infection en hances $P$. multocida adherence on respiratory epithelial cells. Vet Microbiol 220: 33-38.

25. Sudaryatma PE et al. 2019. Co-infection of epithelial cells established from the upper and lower bovine respiratory tract with bovine respiratory syncytial virus and bacteria. Vet Microbiol 235: 80-85.
26. Thanthrige DN et al. 2018. A novel multiplex PCR-electronic microarray assay for rapid and simultaneous detection of bovine respiratory and enteric pathogens. $J$ Virol Methods 261: 51-62.

27. Wathes DC, Oguejiofor CF, Thomas C, Cheng Z. 2020. Importance of viral disease in dairy cow fertility. Engineering 6: 26-33.

28. Zhao $\mathbf{G}$ et al. 2018. Development of a recombinase polymerase amplification combined with a lateral flow dipstick assay for rapid detection of the Mycoplasma bovis. BMC Vet Res 14: 1-10.

29. Zhao G, Wang H, Hou P, Xia X, He H. 2018. A lateral flow dipstick combined with reverse transcription recombinase polymerase amplification for rapid and visual detection of the bovine respirovirus 3. Mol Cell Probes 41: $22-26$.

30. Zhao G, He H, Wang H. 2019. Use of a recombinase polymerase amplification commercial kit for rapid visual detection of P. multocida. BMC Vet Res 15: 1-8.

\section{Asociación Cooperadora de la Facultad de Ciencias Veterinarias Universidad Nacional del Nordeste}

Personería Jurídica $\mathrm{N}^{\circ} 647 / 92$ y $912 / 00$

Sargento Cabral 2139

3400 Corrientes

Argentina

La Asociación Cooperadora de la Facultad de Ciencias Veterinarias de la UNNE fue constituida el 10 de diciembre del año 1991 como entidad de bien público, con el objeto de promover y coadyuvar las actividades científicas, educativas y culturales relacionadas con las Ciencias Veterinarias. En tal sentido, implementa acciones para colaborar con la enseñanza, extensión, actualización y difusión científica que realiza dicha casa de estudios.

\section{Beneficios que brinda a sus asociados:}

- Fotocopias con descuentos especiales en la Fotocopiadora Copias.com que funciona dentro del predio de la Facultad de Ciencias Veterinarias.

- Descuentos para la adquisición de libros de distintas editoriales.

- Descuentos especiales en otros rubros.

Tel. (0379) 4425753 interno 186 • Página Web www.vet.unne.edu.ar • E-mail: cooperadora $@$ vet.unne.edu.ar 